\title{
Abdominal obesity vs general obesity for identifying arterial stiffness, subclinical atherosclerosis and wave reflection in healthy, diabetics and hypertensive
}

\author{
Jose I Recio-Rodriguez ${ }^{1 *}$, Manuel A Gomez-Marcos', Maria C Patino-Alonso², Cristina Agudo-Conde',
} Emiliano Rodriguez-Sanchez ${ }^{1}$ and Luis Garcia-Ortiz ${ }^{1}$, for the Vasorisk group

\begin{abstract}
Background: Our aim was to analyze the relationship between abdominal obesity and general obesity, with subclinical atherosclerosis, arterial stiffness and wave reflection in healthy, diabetics and hypertensive subjects.

Methods: A cross-sectional descriptive study was made of 305 individuals (diabetics 32.8\%, hypertensive subjects 37.0\% and healthy individuals 30.2\%). Measurements: Body mass index (BMI), waist circumference (WC), body fat percentage (BFP) and waist/height ratio (WHtR). Arterial stiffness was assessed according to pulse wave velocity (PWV), intima-media thickness of the common carotid artery (C-IMT), augmentation index (central and peripheral), ankle-brachial index $(\mathrm{ABI})$, and central and peripheral pulse pressure.

Results: WC and WHtR showed a positive correlation to PWV and C-IMT in the studied groups. After adjusting for age, gender, high sensitivity c-reactive protein, serum glucose and the presence of diabetes, hypertension,

smoking, dyslipidemia, antidiabetic drugs, lipid-lowering drugs, and atherosclerotic plaques, it was seen that for every 0.1 point increase in WHtR, and for every $\mathrm{cm}$ increase in WC, the PWV increased 0.041 and $0.029 \mathrm{~m} / \mathrm{sec}$, and C-IMT increased $0.001 \mathrm{~mm}$ and $0.001 \mathrm{~mm}$, respectively.

Conclusions: The measures of abdominal obesity (WHtR and WC) correlates better than BMI and BFP with arterial stiffness evaluated by PWV, and with subclinical atherosclerosis evaluated by C-IMT, independently of the presence of diabetes or hypertension.
\end{abstract}

Trial Registration: Clinical Trials.gov Identifier: NCT01325064

\section{Background}

Obesity is a determinant factor in the development of cardiovascular diseases, and is associated to an increased incidence of hypertension, diabetes, metabolic syndrome and cardiac target organ damage [1-4].

Some studies have shown measures of abdominal obesity such as waist circumference (WC), waist to hip ratio and waist/height ratio (WHtR) to be the parameters best correlated with cardiovascular disease and mortality [5-13]. In contrast, other studies have not found sufficient

\footnotetext{
* Correspondence: donrecio@gmail.com

'Primary Care Research Unit, La Alamedilla Health Center, SACYL, REDIAPP. Salamanca, Spain

Full list of author information is available at the end of the article
}

evidence that these measures of abdominal obesity are superior to body mass index (BMI) in predicting cardiovascular and cardiometabolic risk [14-21].

The vascular structure and function can be assessed through the indices of subclinical atherosclerosis, arterial stiffness and wave reflection [22]. A relationship has been found between measures that assess excess body weight or obesity to certain parameters that measure arterial stiffness and subclinical atherosclerosis, such as the pulse wave velocity (PWV) and the intima-media thickness of the common carotid artery (C-IMT), though their correlation to the augmentation index is not clear [23-25]. However, to our knowledge, no studies have examined

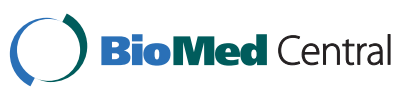

(c) 2012 Recio-Rodriguez et al; licensee BioMed Central Ltd. This is an Open Access article distributed under the terms of the Creative Commons Attribution License (http://creativecommons.org/licenses/by/2.0), which permits unrestricted use, distribution, and reproduction in any medium, provided the original work is properly cited. 
whether this relationship differs in healthy subjects, diabetics and hypertensive individuals.

The present study explores the relationship between anthropometric indices that assess abdominal obesity (WC, WHtR) and general obesity (BMI and body fat percentage (BFP)), with parameters that measure arterial stiffness (PWV, central and peripheral pulse pressure), subclinical atherosclerosis (C-IMT and and ankle-brachial index (ABI)) and wave reflection (central augmentation index) in healthy, diabetics and hypertensive subjects.

\section{Methods}

A cross-sectional study was performed in a primary care setting. We consecutively included all the hypertensive, diabetics and healthy patients, that visited their family doctor, aged 20-75 years, from January 2010 to January 2011. After dealing with the reason for consultation, the patients were referred to the research unit for the assessment of cardiovascular risk. Exclusion criteria were: patients with intermittent claudication, and previous cardiovascular events, patients unable to comply with the protocol requirements (psychological and/or cognitive disorders, failure to cooperate, educational limitations and problems for understanding written language, failure to sign the informed consent document), patients participating or who will participate in a clinical trial during the study. The sample size to detect a minimum correlation coefficient between anthropometric parameters and arterial stiffness parameters of 0.3 in diabetic, hypertensive and healthy subject with two-sided type I error rate of $5 \%$ and $80 \%$ power was estimated to be 85 individuals each group (total 255). We considered enough with the 305 subjects included in the study. The study was approved by an independent ethics committee of Salamanca University Hospital (Spain) and all participants gave written informed consent according to the general recommendations of the Declaration of Helsinki [26].

\section{Variables and measurement instruments Anthropometric measurements}

Body weight was determined on two occasions using a homologated electronic scale (Seca 770) following due calibration (precision $\pm 0.1 \mathrm{~kg}$ ), with the patient wearing light clothing and no shoes. These readings was rounded to $100 \mathrm{~g}$. Height in turn was measured with a portable system (Seca 222), recording the average of two readings, and with the patient shoeless in the standing position. The values was rounded to the closest centimeter. Body mass index (BMI) was calculated as weight $(\mathrm{kg})$ divided by height squared $\left(\mathrm{m}^{2}\right)$. A value higher of $30 \mathrm{Kg} / \mathrm{m}^{2}$ was considered obesity. Waist circumference was measured as following: the upper border of the iliac crests are located, and the tape is wrapped around above this point, parallel to the floor, ensuring that it is adjusted without compressing the skin. The reading is taken at the end of a normal breath according to the recommendations of the 2007 SEEDO Conference $[27,28]$, whereas normal when the value is below $102 \mathrm{~cm}$ in men and $88 \mathrm{~cm}$ in women. WHtR was calculated as height $(\mathrm{cm})$ divided by waist circumference $(\mathrm{cm})$, whereas normal when the value is below 0.5 [29]. Body fat percentage was measured using a body fat monitor (OMRON, model BF306).

\section{Blood pressure}

Office or clinical blood pressure was measured involving three measurements of systolic and diastolic blood pressure, using the average of the last two measurements, with a validated OMRON model M7 sphygmomanometer (Omron Health Care, Kyoto, Japan). Measures were taken in the right upper arm of participants in a sedentary position while they were seated after having rested for at least $5 \mathrm{~min}$. with an appropriately sized cuff based on the measurement of arm circumference and following the recommendations of the European Society of Hypertension [30].

Central blood pressure and central and peripheral augmentation index (CAIx, PAIx) were estimated using the SphygmoCor System. With the patient sitting and the arm resting on a rigid surface, pulse wave in radial artery was tested and used to estimate the aortic pulse wave using a mathematic transformation. Inter-observer reliability was assessed before the start of the study using an intraclass correlation of 0.974 ( $95 \%$ CI: 0.936 to 0.989 ) in repeated measures in 22 subjects and with Bland-Altman analysis, where inter-observer agreement limits were 0.454 (95\% CI: -9.876 to 10.785 ).

Pulse wave velocity (PWV) was estimated with the SphygmoCor System (AtCor Medical Pty Ltd Head Office, West Ryde, Australia), with the patient in the supine position. The pulse wave of the carotid and femoral arteries were analyzed, estimating the delay with respect to the ECG wave and calculating PWV. Distance measurements were taken with a measuring tape from the sternal notch to the carotid and femoral arteries at the sensor location. PWV higher than $12 \mathrm{~m} / \mathrm{sec}$ was considered abnormal [31]. Assessment of carotid intima-media thickness (C-IMT) Carotid ultrasonography to assess IMT was performed by two investigators trained for this purpose before starting the study. Reliability was evaluated before the study began, using the intraclass correlation coefficient, which showed values of 0.974 (95\%CI: 0.935 to 0.990 ) for intraobserver agreement on repeated measurements in 20 subjects, and 0.897 (95\% CI: 0.740 to 0.959 ) for interobserver agreement. In turn, according to the BlandAltman analysis, the limit of inter-observer agreement was 0.022 (95\%CI: -0.053 to 0.098$)$ and the limit of intraobserver agreement was 0.012 (95\%CI: -0.034 to 0.059 ). A Sonosite Micromax ultrasound device paired with a 5$10 \mathrm{MHz}$ multifrequency high-resolution linear transducer with Sonocal software was used for performing automatic 
measurements of IMT, in order to optimize reproducibility. Measurements were made of the common carotid artery after the examination of a longitudinal section of $10 \mathrm{~mm}$ at a distance of $1 \mathrm{~cm}$ from the bifurcation, performing measurements in the proximal wall, and in the distal wall in the lateral, anterior and posterior projections, following an axis perpendicular to the artery to discriminate two lines - one for the intima-blood interface and the other for the media-adventitia interface. A total of 6 measurements were obtained of the right carotid and another 6 of the left carotid, using average values (average IMT) calculated automatically by the software. The measurements were obtained with the subject lying down, with the head extended and slightly turned opposite to the carotid examined, following the recommendations of the Manheim Carotid Intima-Media Thickness Consensus [32]. The average IMT was considered abnormal if it measured $>0.90 \mathrm{~mm}$, or if there were atherosclerotic plaques with a diameter of $1.5 \mathrm{~mm}$ or a focal increase of $0.5 \mathrm{~mm}$ or $50 \%$ of the adjacent IMT [31].

Evaluation of peripheral artery involvement This was evaluated using the ankle-brachial index (ABI), performed in the morning without having consumed coffee or tobacco for at least 8 hours prior to measuring and an ambient temperature of $22-24^{\circ} \mathrm{C}$. With the feet uncovered, in a supine decubitus position after 20 minutes of rest, the pressure in the lower extremities and blood pressure in both arms was measured using a portable WatchBP Office ABI (Microlife AG Swiss Corporation). The ABI was calculated automatically for each foot by dividing the higher of the two systolic pressures in the ankle by the highest measurement of the two systolic pressures in the arm. ABI lower than 0.9 was considered abnormal $[31,33]$.

Blood samples were collected in the morning, after patient fasting $8 \mathrm{~h}$. Basal glucose, HDL cholesterol, LDL cholesterol, total cholesterol, triglycerides and fibrinogen were determined. High sensitivity $\mathrm{C}$-reactive protein was determined by the nephelometric method (Beckman Instrument APS; Beckman Coulter Inc., Fullerton, CA, USA) [34]. The parameters were measured on a blind basis in the Hospital Biochemistry laboratory using standard automatized techniques. The HOMA index was calculated as fasting insulin concentration $(\mu \mathrm{U} / \mathrm{mL}) \times$ fasting glucose concentration $(\mathrm{mmol} / \mathrm{L}) / 22.5$.

The individuals performing the different tests were blinded to the clinical data of the patient.

\section{Statistical analysis}

The continuous variables were expressed as mean \pm standard deviation, while frequency distribution was used in the qualitative variables. The difference in means in quantitative variables between the three groups has been analyzed using the ANOVA for independent samples. Non-normally distributed variables were evaluated by the
Kruskal-Wallis test, and they were log transformed for further analysis. Because of their skewed distribution, glucose, triglyceride, high sensitivity c-reactive protein and HOMA were presented as median and interquartile range. Pearson's or Spearman correlation coefficient were used to estimate the relationship between the quantitative variables, while the chi-square test was used to associate the qualitative variables. We performed multiple linear regression analysis using PWV, C-IMT, CAIx as dependent variables and the anthropometrics indices as predictors following three models. First model without adjustment. In a second model to include as adjustment variables age and gender (male $=1$; female $=0$ ), in the third model the presence of other cardiovascular risk factors (diabetes, hypertension, lipid lowering drugs, and smoking) and finally in the fourth model: systolic blood presure, total cholesterol, high sensitivity C-reactive protein, serum glucose, antidiabetic drugs and atherosclerotic plaques. The data were analyzed using the SPSS version 18.0 statistical package (SPSS Inc., Chicago, Illinois, USA). A value of $\mathrm{P}<0.05$ was considered statistically significant.

\section{Results}

Table 1 shows the clinical and demographic characteristics of the 305 subjects included in the study (diabetics $32.8 \%$, hypertensive subjects $37.0 \%$ and healthy individuals $30.2 \%$ ), together with the anthropometric measures, inflammatory markers, central and peripheral arterial pressure, measures of arterial stiffness, subclinical atherosclerosis and wave reflection.

The diabetics were older, with a higher percentage of dyslipidemia and a greater proportion of abdominal obesity and BMI $>30$ than the hypertensive and healthy subjects $(\mathrm{p}<0.01)$, while WHtR $>0.5$ was similar to that recorded in the other groups $(\mathrm{p}=0.066)$ (Figure 1$)$.

The correlation between different anthropometric measures was high between BMI and the two abdominal obesity measures (WC and WHtR) ( $r=0.858$ and 0.877), moderate between BFP and BMI and WHtR, respectively $(\mathrm{r}=0.506$ and 0.538$)$, and discrete between BFP and WC ( $\mathrm{r}=0.286)$.

The parameters assessing abdominal obesity (WC and WHtR) showed a positive correlation to PWV and C-IMT in the studied groups. BFP was positively correlated to the central augmentation index (CAIx) in healthy individuals, and to the central and peripheral augmentation indices in healthy and hypertensive subjects. No relationship between the arterial pressure values and anthropometric parameters was recorded in the hypertensive individuals. Lastly, a positive correlation was observed between inflammatory markers such as high sensitivity C-reactive protein (hs-CRP) and fibrinogen, and most of the anthropometric measures in diabetics or hypertensive individuals (Table 2). 
Table 1 General demographic and clinics characteristics

\begin{tabular}{|c|c|c|c|c|c|}
\hline & Global $n=305$ & Healthy $n=92(30.20)$ & Diabetic $n=100(32.80)$ & Hypertensive $n=113(37.00)$ & $p$ \\
\hline Age & $53.37 \pm 12.04$ & $48.56 \pm 11.85$ & $59.29 \pm 10.56$ & $52.05 \pm 11.33$ & $<0.001$ \\
\hline Male (n. \%) & $163(53.40)$ & $34(37.00)$ & $65(65.00)$ & $64(56.60)$ & $<0.001$ \\
\hline Female (n.\%) & $142(46.60)$ & $58(63.00)$ & $35(35.00)$ & $49(43.40)$ & $<0.001$ \\
\hline Dyslipidemia (n. \%) & $121(39.70)$ & $12(13.00)$ & $73(73.00)$ & $36(31.90)$ & $<0.001$ \\
\hline Smoking (n. \%) & $71(23.30)$ & $24(26.10)$ & $20(20.00)$ & $27(23.90)$ & 0.597 \\
\hline BMI $\left(\mathrm{Kg} / \mathrm{m}^{2}\right)$ & $27.92 \pm 4.53$ & $25.73 \pm 3.49$ & $29.90 \pm 5.24$ & $27.96 \pm 3.75$ & $<0.001$ \\
\hline Waist circumference $(\mathrm{cm})$. & $95.80 \pm 12.31$ & $89.57 \pm 9.53$ & $102.32 \pm 12.63$ & $95.16 \pm 11.25$ & $<0.001$ \\
\hline Body fat percentage & $34.06 \pm 6.97$ & $33.89 \pm 7.04$ & $34.67 \pm 7.49$ & $33.69 \pm 6.47$ & 0.589 \\
\hline Waist to height ratio & $0.58 \pm 0.08$ & $0.54 \pm 0.05$ & $0.62 \pm 0.09$ & $0.57 \pm 0.06$ & $<0.001$ \\
\hline Total cholesterol (mg/dL) & $205.36 \pm 40.40$ & $207.68 \pm 38.70$ & $189.81 \pm 38.33$ & $217.23 \pm 39.41$ & $<0.001$ \\
\hline HDL-cholesterol (mg/dL) & $53.85 \pm 13.70$ & $58.10 \pm 14.29$ & $48.92 \pm 11.13$ & $54.82 \pm 14.05$ & $<0.001$ \\
\hline LDL-cholesterol (mg/dL) & $126.28 \pm 34.83$ & $129.97 \pm 34.31$ & $111.19 \pm 29.82$ & $136.94 \pm 35.01$ & $<0.001$ \\
\hline Triglyceride (mg/dL) & $104(74-144.5)$ & $80(60.25-114.00)$ & $118(86.25-174.25)$ & 109 (83.00-153.50) & $<0.001$ \\
\hline Serum glucose (mg/dL) & $89(80-107.5)$ & $82(77.00-88.00)$ & $130(106.00-149.75)$ & 85 (78.50-93.00) & $<0.001$ \\
\hline hsCRP (mg/dL) & $0.16(0.09-0.33)$ & $0.13(0.06-0.23)$ & $0.17(0.09-0.47)$ & $0.17(0.09-0.29)$ & 0.043 \\
\hline HOMA index & $1.67(0.98-3.02)$ & $1.07(0.70-1.75)$ & $2.43(1.49-4.24)$ & $1.55(1.06-2.75)$ & $<0.001$ \\
\hline Fibrinogen (mg/dL) & $320.52 \pm 62.51$ & $319.88 \pm 60.11$ & $328.77 \pm 67.29$ & $313.73 \pm 59.62$ & 0.224 \\
\hline Office SBP (mmHg) & $133.61 \pm 19.50$ & $115.23 \pm 14.21$ & $137.10 \pm 18.68$ & $145.48 \pm 11.37$ & $<0.001$ \\
\hline Office DBP (mmHg) & $84.21 \pm 12.27$ & $74.40 \pm 8.92$ & $83.10 \pm 11.33$ & $93.18 \pm 8.33$ & $<0.001$ \\
\hline Peripheral pulse pressure $(\mathrm{mmHg})$ & $49.40 \pm 12.77$ & $40.83 \pm 8.93$ & $54.00 \pm 13.39$ & $52.31 \pm 11.46$ & $<0.001$ \\
\hline Central SBP $(\mathrm{mmHg})$ & $125.28 \pm 19.57$ & $107.52 \pm 13.69$ & $128.86 \pm 17.82$ & $137.86 \pm 12.95$ & $<0.001$ \\
\hline Central DBP $(\mathrm{mmHg})$ & $84.87 \pm 12.86$ & $74.71 \pm 9.41$ & $84.31 \pm 11.67$ & $94.36 \pm 8.87$ & $<0.001$ \\
\hline Central Pulse pressure $(\mathrm{mmHg})$ & $40.41 \pm 12.12$ & $32.82 \pm 8.48$ & $44.55 \pm 12.17$ & $43.50 \pm 11.78$ & $<0.001$ \\
\hline $\mathrm{PW}(\mathrm{m} / \mathrm{s})$ & $8.59 \pm 2.29$ & $7.03 \pm 1.42$ & $9.84 \pm 2.35$ & $8.80 \pm 2.08$ & $<0.001$ \\
\hline C-IMT mean (mm.) & $0.71 \pm 0.11$ & $0.64 \pm 0.09$ & $0.77 \pm 0.12$ & $0.70 \pm 0.10$ & $<0.001$ \\
\hline C-IMT maximum (mm.) & $0.88 \pm 0.14$ & $0.80 \pm 0.11$ & $0.96 \pm 0.14$ & $0.87 \pm 0.12$ & $<0.001$ \\
\hline CAlx & $30.33 \pm 12.07$ & $29.27 \pm 13.28$ & $30.77 \pm 11.33$ & $30.89 \pm 11.61$ & 0.592 \\
\hline PAlx & $91.51 \pm 20.67$ & $88.27 \pm 19.74$ & $94.73 \pm 22.96$ & $91.63 \pm 19.11$ & 0.109 \\
\hline$A B \mid$ & $1.11 \pm 0.13$ & $1.15 \pm 0.11$ & $1.09 \pm 0.15$ & $1.11 \pm 0.11$ & 0.002 \\
\hline Antihypertensive drugs (n. \%) & $72(23.6)$ & $0(0.0)$ & $70(70.0)$ & $2(1.8)$ & $<0.001$ \\
\hline Antidiabetic drugs (n. \%) & $87(28.5)$ & $0(0.0)$ & $87(87.0)$ & $0(0.0)$ & $<0.001$ \\
\hline Lipid lowering drugs (n. \%) & $69(22.6)$ & $0(0.0)$ & $58(58.0)$ & $11(9.7)$ & $<0.001$ \\
\hline Atherosclerotic plaques (n. \%) & $37(12.1)$ & $1(1.1)$ & $25(25.0)$ & $11(9.7)$ & $<0.001$ \\
\hline
\end{tabular}

BMI: Body mass index. HDL: High-density lipoprotein. LDL: Low-density lipoprotein. hsCRP: High sensitivity c-reactive protein. SBP: Systolic blood pressure. DBP: Diastolic blood pressure. PWV: Pulse wave velocity. C-IMT:Intima-media thickness. CAlx: Central augmentation index. PAIx: Peripheral augmentation index. ABI: ankle-brachial index.

Data for qualitative variables are expressed as $\mathrm{n}(\%)$ and quantitative variables as mean \pm standard deviation or mean (interquartile range) p: statistically significant differences $(p<0.05)$.

Figure 2 shows the simple regression straight line of PWV versus the anthropometric parameters.

After adjusting for age, gender and cardiovascular risk factors, the multiple regression analysis found that for every 0.1 point increase in WHtR, the PWV increased $0.041 \mathrm{~m} / \mathrm{sec}$ and C-IMT increased 0.001 $\mathrm{mm}$. Likewise, a $1 \mathrm{~cm}$ increase in WC implied an increase of $0.029 \mathrm{~m} / \mathrm{sec}$ in PWV, $0.001 \mathrm{~mm}$ in C-IMT, and a decrease of 0.141 in CAIx. A $1 \mathrm{~kg} / \mathrm{m}^{2}$ increase in BMI in turn implied an increase of $0.052 \mathrm{~m} / \mathrm{sec}$ in PWV, and a decrease of 0.270 in CAIx. Lastly, every $1 \%$ increase in BFP implied and a decrease of 0.284 in CAIx (Table 3).

\section{Discussion}

The present study shows that the measures of abdominal obesity (WHtR and WC) are better than the general obesity indicators (BMI and BFP) in predicting arterial stiffness as evaluated by PWV and subclinical atherosclerosis evaluated by C-IMT, independently of the presence of diabetes or hypertension. Therefore, WC and WHtR are the most useful parameters for estimating arterial stiffness in clinical practice.

A number of studies have analyzed the association between C-IMT and abdominal and general obesity parameters. Yan et al. [35] reported a good correlation between BMI and WC, though the waist-to-hip ratio was 


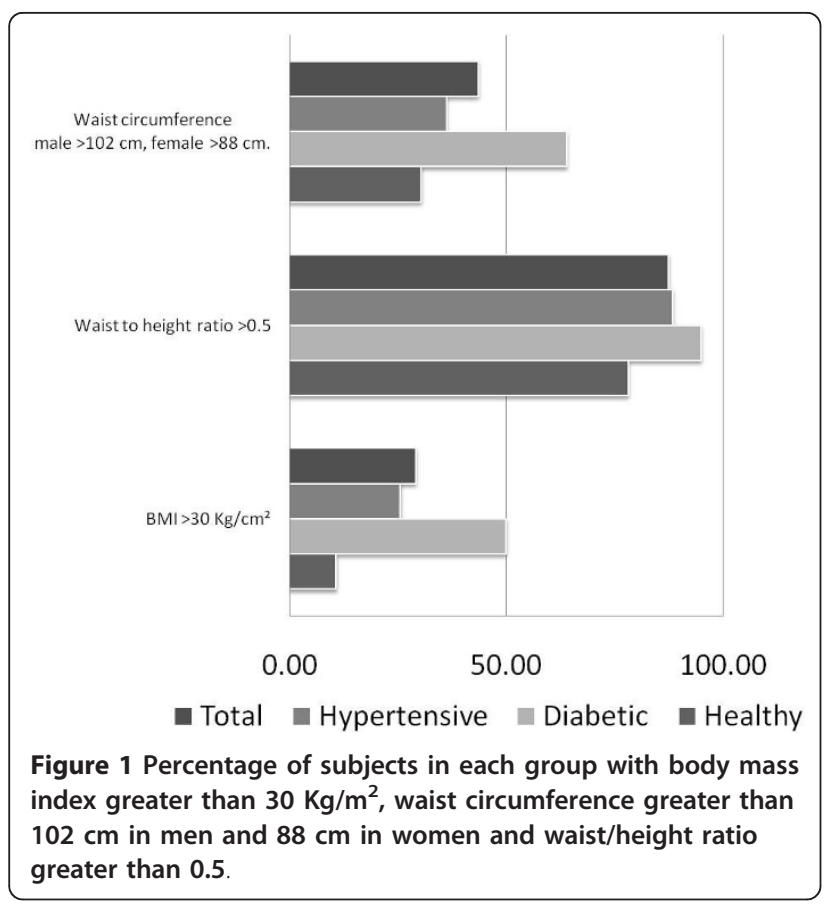

the parameter that best predicted C-IMT. In the study of Maher et al. [36], after adjusting for age, gender and the presence of cardiovascular risk factors, WHtR and BMI were seen to maintain their relationship to C-IMT. In both studies, and coinciding with the results of earlier publications [37], the measures that adjust WC were seen to be the best predictors of C-IMT. We did not measure the waist-to-hip-ratio, though another parameter that adjusts WC according to height was used, i.e., WHtR.
However, in contrast to other studies, our findings were confirmed in all three patient groups considered (healthy individuals, diabetics and hypertensive subjects).

Likewise, we found a positive correlation between the anthropometric measures and PWV. Our results are in line with the observations of Ko et al. [23] and Wildman et al. [25]. Again, the behavior proved similar in all three groups studied.

Since the arterial stiffness is a surrogate marker between the appearance of risk factors and cardiovascular outcomes, our findings support the importance of anthropometric measures as a risk factors [38].

Maher et al. examined the relationship between the augmentation index and the anthropometric indices only age being found to remain on performing the multivariate analysis. We did record a significant relationship, though of a negative sign. This may have been due to the fact that in our series the obese individuals (BMI $>30 \mathrm{~kg} / \mathrm{m}^{2}$ ) presented a CAIx of 31.3 versus 28.0 in those with BMI $<30$. In the case of BFP, the behavior was not uniform among the three groups. BFP was positively correlated to the CAIx in healthy individuals, and to the central and peripheral augmentation indices in healthy and hypertensive subjects - no such relationship being observed among diabetics.

In contrast to Tison et al. [39], we observed no relationship between the different anthropometric indices and $\mathrm{ABI}$, and no consistent relationship with the arterial pressure measures (central and peripheral). This fact was more relevant in the hypertensive group - antihypertensive treatment being the most likely explanation.

Table 2 Pearson correlations between arterial stiffness and anthropometrics measurements

\begin{tabular}{|c|c|c|c|c|c|c|c|c|c|c|c|c|}
\hline & \multicolumn{4}{|c|}{ Healthy $n=92(30.20)$} & \multirow[b]{2}{*}{ BMI } & \multicolumn{4}{|c|}{ Diabetic $n=100(32.80)$} & \multicolumn{3}{|c|}{ Hypertensive $n=113(37.00$} \\
\hline & BMI & WC & BFP & $\mathrm{WHtR}$ & & WC & BFP & $\mathrm{WHtR}$ & BMl & WC & BFP & WHtR \\
\hline Office SBP (mmHg) & 0.114 & $0.285^{* *}$ & $-0.257^{*}$ & 0.126 & $0.299^{* *}$ & $0.379^{* *}$ & 0.034 & $0.343^{* *}$ & 0.009 & 0.016 & -0.051 & 0.058 \\
\hline Office DBP (mmHg) & 0.141 & 0.195 & -0.151 & 0.112 & $0.457^{* *}$ & $0.433^{* *}$ & 0.142 & $0.409^{* *}$ & 0.037 & 0.045 & 0.022 & 0.009 \\
\hline Peripheral pulse pressure (mmHg) & 0.041 & $0.259^{*}$ & $-0.258^{*}$ & 0.089 & 0.031 & 0.163 & -0.073 & 0.133 & -0.018 & -0.017 & -0.070 & 0.052 \\
\hline Central SBP (mmHg) & 0.068 & 0.187 & -0.140 & 0.122 & $0.267^{*}$ & $0.322^{* *}$ & 0.033 & $0.315^{* *}$ & -0.146 & -0.156 & -0.037 & -0.041 \\
\hline Central DBP (mmHg) & $0.211^{*}$ & $0.249^{*}$ & -0.125 & 0.156 & $0.367^{* *}$ & $0.350^{* *}$ & 0.050 & $0.316^{* *}$ & 0.022 & 0.032 & 0.044 & 0.021 \\
\hline Central Pulse pressure $(\mathrm{mmHg})$ & -0.124 & 0.026 & -0.087 & 0.024 & 0.038 & 0.136 & 0.001 & 0.158 & -0.177 & $-0.195^{*}$ & -0.079 & -0.061 \\
\hline $\operatorname{PWV}(\mathrm{m} / \mathrm{s})$ & 0.078 & $0.209^{*}$ & 0.013 & $0.219^{*}$ & $0.230^{*}$ & $0.342^{* *}$ & 0.163 & $0.357^{* *}$ & $0.232^{*}$ & $0.267^{* *}$ & $0.203^{*}$ & $0.335^{* *}$ \\
\hline C-IMT mean (mm.) & 0.093 & $0.228^{*}$ & 0.008 & $0.271^{* *}$ & 0.053 & $0.229^{*}$ & -0.074 & 0.176 & $0.223^{*}$ & $0.249^{* *}$ & 0.101 & $0.306^{* *}$ \\
\hline C-IMT maximum (mm.) & 0.039 & 0.174 & 0.001 & $0.215^{*}$ & 0.051 & $0.231^{*}$ & -0.072 & 0.177 & $0.257^{* *}$ & $0.280^{* *}$ & 0.108 & $0.325^{* *}$ \\
\hline CAlx & $-0.207^{*}$ & -0.193 & $0.306^{* *}$ & 0.054 & -0.105 & -0.150 & 0.063 & -0.007 & $-0.284^{* *}$ & $-0.285^{* *}$ & 0.106 & -0.083 \\
\hline PAlx & $-0.215^{*}$ & -0.172 & $0.300^{* *}$ & 0.069 & -0.057 & -0.120 & 0.167 & 0.027 & -0.115 & $-0.229^{*}$ & $0.263^{* *}$ & 0.031 \\
\hline$A B \mid$ & 0.063 & 0.090 & 0.205 & 0.132 & -0.114 & -0.149 & -0.075 & -0.125 & 0.031 & -0.060 & -0.073 & 0.010 \\
\hline Fibrinogen (mg/dL) & 0.172 & -0.015 & $0.299 * *$ & 0.211 & $0.337^{* *}$ & $0.401^{* *}$ & $0.287^{* *}$ & $0.435^{* *}$ & $0.202^{*}$ & 0.184 & $0.233^{*}$ & $0.257^{* *}$ \\
\hline $\mathrm{hsCRP}(\mathrm{mg} / \mathrm{dL})$ & $0.306^{* *}$ & $0.288^{* *}$ & 0.180 & $0.301^{* *}$ & $0.442^{* *}$ & $0.442^{* *}$ & $0.356^{* *}$ & $0.475^{* *}$ & $0.214^{*}$ & $0.266^{* *}$ & $0.251^{*}$ & $0.316^{* *}$ \\
\hline HOMA index & 0.246 & 0.126 & 0.087 & 0.093 & $0.231^{*}$ & $0.303^{* *}$ & 0.179 & $0.247^{*}$ & $0.427^{* *}$ & $0.444^{* *}$ & 0.108 & $0.465^{* *}$ \\
\hline
\end{tabular}

BMI: Body mass index. WC: Waist circumference. BFP: Body fat percentage. WHtR: Waist to height ratio SBP: Systolic blood pressure. DBP: Diastolic blood pressure. PWV: Pulse wave velocity. C-IMT: Carotid intima-media thickness. CAlx: Central augmentation index. PAlx: Peripheral augmentation index. ABI: ankle-brachial index. hsCRP: High sensitivity c-reactive protein. p: statistically significant differences ${ }^{*} p<0.05 *{ }^{*} p<0.01$ 


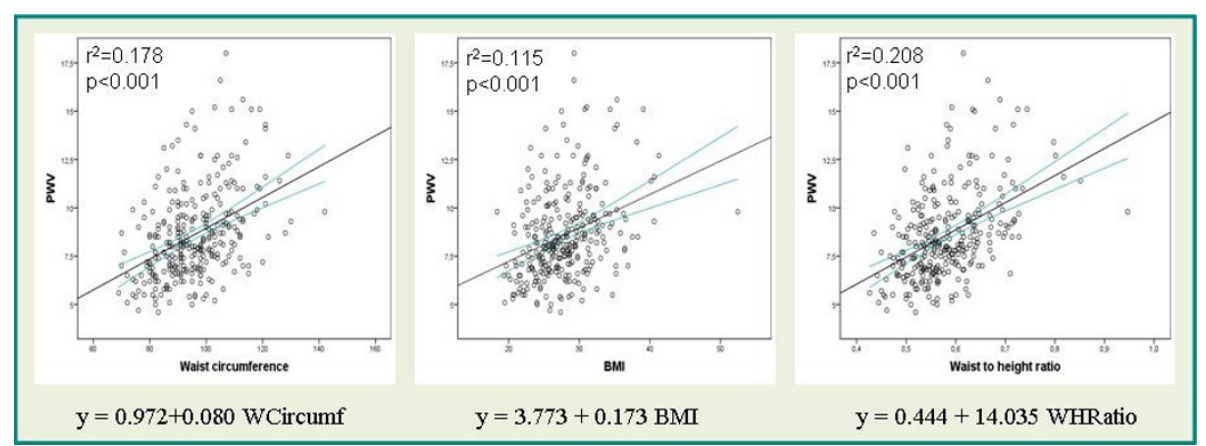

Figure 2 PWV values plotted against anthropometric indices (WC, WHtR and BMI). The figures show regression line.

Table 3 Models with PWV, C-IMT, and CAlx as dependent variables and anthropometric indices as predictors.

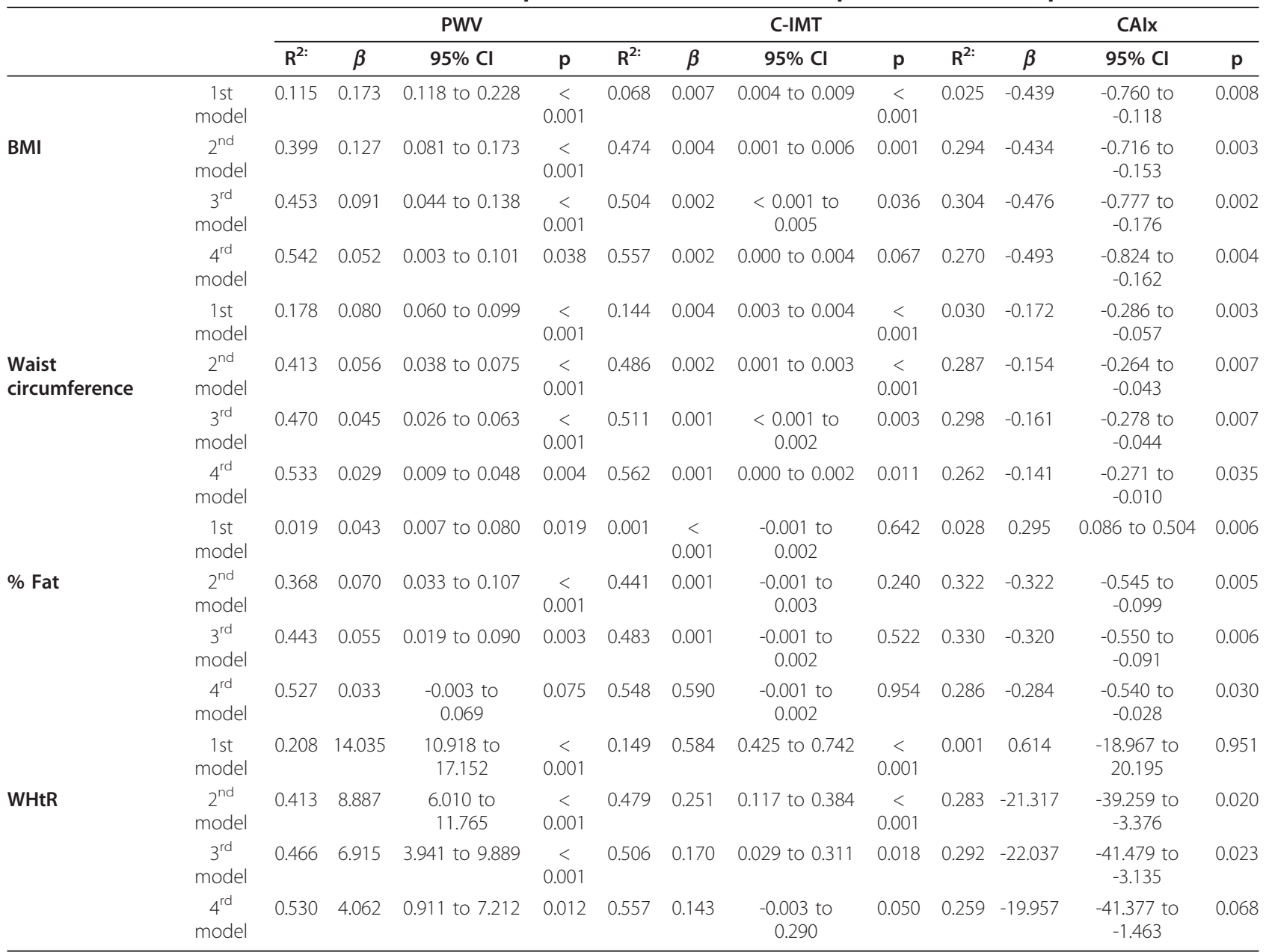

PWV: Pulse wave velocity. C-IMT: Intima media thickness.CAlx: Central augmentation index. BMI: Body mass index. \% Fat: body fat percentage. WHtR: Waist to height ratio.

p: statistically significant differences $(p<0.05)$.

First model: No adjusted.

Second model: Regression model constructed with BMI, waist circumference, body fat percentage and waist height ratio as predictors variables adjusted by gender and age.

Third model: Regression model constructed with BMI, waist circumference, body fat percentage and waist height ratio as predictors variables adjusted by gender, age, to be diabetic, to be hypertensive, lipid lowering drugs and smoking.

Fourth model: Regression model constructed with BMI, waist circumference, body fat percentage and waist height ratio as predictors variables adjusted by gender, age, to be diabetic, to be hypertensive, lipid lowering drugs, smoking, systolic blood pressure, total cholesterol, high sensitivity c-reactive protein, serum glucose, antidiabetic drugs and atherosclerotic plaques. 
The main limitation of our study is its cross-sectional design, which precludes the definition of causality and analysis of the behavior over time of the different stiffness parameters in relation to the different anthropometric indices considered. On the other hand, with a study design of this kind it would also be necessary to increase the sample size, since a larger number of individuals in each group (healthy, diabetic and hypertensive) could help clarify which anthropometric parameters are best related to arterial stiffness in each of them.

\section{Conclusions}

Based on the results obtained in our study, it can be concluded that, independently of the presence of diabetes or hypertension, the measures of abdominal obesity (WHtR and WC) correlates better than BMI and BFP with arterial stiffness and subclinical atherosclerosis evaluated by PWV and C-IMT respectively. However, the association with wave reflection (evaluated by CAIx) was better with general adiposity measures.

\section{List of abbreviations}

BMI: Body mass index; WC: Waist circumference; BFP: Body fat percentage; WHtR: Waist/height ratio; C-IMT: Intima-media thickness of the common carotid artery; PWV: Pulse wave velocity; CAlx: Central augmentation index; ABI: Ankle brachial index.

\section{Acknowledgements}

This project has been supported by Castilla y León Health Service (GRS 498/ A/10), Carlos III Institute of Health of the Ministry of Health of Spain,(RETICS RD06/0018/0027) and Infosalud Fundation.

Vaso risk group

Luis García-Ortiz, Manuel A Gomez-Marcos, José I Recio-Rodríguez, Cristina Agudo-Conde, Maria C Patino-Alonso, Emiliano Rodriguez-Sanchez, Emilio Ramos-Delgado, Luis J González-Elena, Ángel García-García, Javier ParraSánchez, Carmela Rodríguez-Martín, Carmen Castaño-Sánchez, Ángela de Cabo-Laso, Benigna Sánchez-Salgado (1), Carlos Martínez-Salgado, Ana M. Blázquez-Medela (2).

'Unidad de Investigación de Atención Primaria La Alamedilla, Salamanca, Spain.

${ }^{2}$ Unidad de Fisiopatología Renal y Cardiovascular, Instituto Reina Sofía de Investigación Nefrológica, Universidad de Salamanca, Salamanca, Spain

\section{Author details \\ 'Primary Care Research Unit, La Alamedilla Health Center, SACYL, REDIAPP. Salamanca, Spain. ${ }^{2}$ Statistics Department, University of Salamanca, Salamanca, Spain.}

\section{Authors' contributions}

$J I R:$ devised the study, designed the protocol, participated in fund raising, interpretation of results, prepared the manuscript draft and corrected the final version of the manuscript. MAG and ER participated in the study design, interpretation of results, and manuscript review. CA participated in the study design, data collection and manuscript review. MCP performed all analytical methods, interpretation of results, and manuscript review. LG participated in the protocol design, fund raising, analysis of results, and final review of the manuscript. Finally, all authors reviewed and approved the final version of the manuscript.

\section{Competing interests}

The authors declare that they have no competing interests.

Received: 31 October 2011 Accepted: 1 February 2012 Published: 1 February 2012

\section{References}

1. Loehr LR, Rosamond WD, Poole C, McNeill AM, Chang PP, Folsom AR, Chambless LE, Heiss G: Association of multiple anthropometrics of overweight and obesity with incident heart failure: the Atherosclerosis Risk in Communities study. Circ Heart Fail 2009, 2:18-24.

2. Turkbey EB, McClelland RL, Kronmal RA, Burke GL, Bild DE, Tracy RP, Arai AE, Lima JA, Bluemke DA: The impact of obesity on the left ventricle: the Multi-Ethnic Study of Atherosclerosis (MESA). JACC Cardiovasc Imaging 2010, 3:266-274.

3. Cheriyath P, Duan Y, Qian Z, Nambiar L, Liao D: Obesity, physical activity and the development of metabolic syndrome: the Atherosclerosis Risk in Communities study. Eur J Cardiovasc Prev Rehabil 2010, 17:309-313.

4. Hu YH, Reilly KH, Liang YJ, Xi B, Liu JT, Xu DJ, Yan YK, Xie B, Li XY: Increase in Body Mass Index, Waist Circumference and Waist-to-height Ratio is Associated with High Blood Pressure in Children and Adolescents in China. J Int Med Res 2011, 39:23-32.

5. de Koning L, Merchant AT, Pogue J, Anand SS: Waist circumference and waist-to-hip ratio as predictors of cardiovascular events: meta-regression analysis of prospective studies. Eur Heart J 2007, 28:850-856.

6. Coutinho T, Goel K, Correa de Sa D, Kragelund C, Kanaya AM, Zeller M, Park JS, Kober L, Torp-Pedersen C, Cottin Y, Lorgis L, Lee SH, Kim YJ, Thomas R, Roger VL, Somers VK, Lopez-Jimenez F: Central obesity and survival in subjects with coronary artery disease: a systematic review of the literature and collaborative analysis with individual subject data. $J$ Am Coll Cardiol 2011, 57:1877-1886.

7. Schneider HJ, Klotsche J, Silber S, Stalla GK, Wittchen HU: Measuring abdominal obesity: effects of height on distribution of cardiometabolic risk factors risk using waist circumference and waist-to-height ratio. Diabetes Care 2011, 34:e7.

8. Dhaliwal SS, Welborn TA: Central obesity and multivariable cardiovascular risk as assessed by the Framingham prediction scores. Am J Cardiol 2009, 103:1403-1407.

9. Czernichow S, Kengne AP, Stamatakis E, Hamer M, Batty GD: Body mass index, waist circumference and waist-hip ratio: which is the better discriminator of cardiovascular disease mortality risk? Evidence from an individual-participant meta-analysis of 82864 participants from nine cohort studies. Obes Rev 2011.

10. Sehested TS, Hansen TW, Olsen MH, Abildstrom SZ, Rasmussen S, Ibsen H, Torp-Pedersen C, Madsbad S, Jeppesen J: Measures of overweight and obesity and risk of cardiovascular disease: a population-based study. Eur J Cardiovasc Prev Rehabil 2010, 17:486-490.

11. Schneider HJ, Friedrich N, Klotsche J, Pieper L, Nauck M, John U, Dorr M, Felix S, Lehnert H, Pittrow D, Silber S, Volzke H, Stalla GK, Wallaschofski $H$, Wittchen HU: The predictive value of different measures of obesity for incident cardiovascular events and mortality. I Clin Endocrinol Metab 2010, 95:1777-1785.

12. Park SH, Choi SJ, Lee KS, Park HY: Waist circumference and waist-toheight ratio as predictors of cardiovascular disease risk in Korean adults. Circ J 2009, 73:1643-1650.

13. Lee CM, Huxley RR, Wildman RP, Woodward M: Indices of abdominal obesity are better discriminators of cardiovascular risk factors than BMI: a meta-analysis. J Clin Epidemiol 2008, 61:646-653.

14. Liu Y, Tong G, Tong W, Lu L, Qin X: Can body mass index, waist circumference, waist-hip ratio and waist-height ratio predict the presence of multiple metabolic risk factors in Chinese subjects? BMC Public Health 2011, 11:35.

15. Qiao $Q$, Nyamdorj $R$ : Is the association of type II diabetes with waist circumference or waist-to-hip ratio stronger than that with body mass index? Eur J Clin Nutr 2010, 64:30-34.

16. Tuan NT, Adair LS, Stevens J, Popkin BM: Prediction of hypertension by different anthropometric indices in adults: the change in estimate approach. Public Health Nutr 2010, 13:639-646.

17. Taylor AE, Ebrahim S, Ben-Shlomo Y, Martin RM, Whincup PH, Yarnell JW, Wannamethee SG, Lawlor DA: Comparison of the associations of body mass index and measures of central adiposity and fat mass with coronary heart disease, diabetes, and all-cause mortality: a study using data from 4 UK cohorts. Am J Clin Nutr 2010, 91:547-556.

18. Freiberg MS, Pencina MJ, D'Agostino RB, Lanier K, Wilson PW, Vasan RS: BMI vs. waist circumference for identifying vascular risk. Obesity (Silver Spring) 2008, 16:463-469. 
19. Wang F, Wu S, Song Y, Tang X, Marshall R, Liang M, Wu Y, Qin X, Chen D, Hu Y: Waist circumference, body mass index and waist to hip ratio for prediction of the metabolic syndrome in Chinese. Nutr Metab Cardiovasc Dis 2009, 19:542-547.

20. Palacios C, Perez CM, Guzman M, Ortiz AP, Ayala A, Suarez E: Association between adiposity indices and cardiometabolic risk factors among adults living in Puerto Rico. Public Health Nutr 2011, 1-10.

21. Boffetta P, McLerran D, Chen Y, Inoue M, Sinha R, He J, Gupta PC, Tsugane S, Irie F, Tamakoshi A, Gao YT, Shu XO, Wang R, Tsuji I, Kuriyama S, Matsuo K, Satoh H, Chen CJ, Yuan JM, Yoo KY, Ahsan H, Pan WH, Gu D, Pednekar MS, Sasazuki S, Sairenchi T, Yang G, Xiang YB, Nagai M, Tanaka H, et al: Body Mass Index and Diabetes in Asia: A Cross-Sectional Pooled Analysis of 900,000 Individuals in the Asia Cohort Consortium. PLoS One 2011, 6:e19930.

22. Wykretowicz A, Gerstenberger P, Guzik P, Milewska A, Krauze T, Adamska K, Rutkowska A, Wysocki H: Arterial stiffness in relation to subclinical atherosclerosis. Eur J Clin Invest 2009, 39:11-16.

23. Ko MJ, Kim MK, Shin J, Choi BY: Relations of pulse wave velocity to waist circumference independent of hip circumference. Epidemiol Health 2010, 32:e2010004.

24. Rider OJ, Tayal U, Francis JM, Ali MK, Robinson MR, Byrne JP, Clarke K, Neubauer S: The effect of obesity and weight loss on aortic pulse wave velocity as assessed by magnetic resonance imaging. Obesity (Silver Spring) 2010, 18:2311-2316.

25. Wildman RP, Mackey RH, Bostom A, Thompson T, Sutton-Tyrrell K: Measures of obesity are associated with vascular stiffness in young and older adults. Hypertension 2003, 42:468-473.

26. World Medical Association declaration of Helsinki. Recommendations guiding physicians in biomedical research involving human subjects. JAMA 1997, 277:925-926.

27. Ross R, Berentzen T, Bradshaw AJ, Janssen I, Kahn HS, Katzmarzyk PT, Kuk JL, Seidell JC, Snijder MB, Sorensen TI, Despres JP: Does the relationship between waist circumference, morbidity and mortality depend on measurement protocol for waist circumference? Obes Rev 2008, 9:312-325.

28. Salas-Salvado J, Rubio MA, Barbany M, Moreno B: [SEEDO 2007 Consensus for the evaluation of overweight and obesity and the establishment of therapeutic intervention criteria]. Med Clin (Barc) 2007, 128:184-196, quiz 181 p following 200

29. Browning LM, Hsieh SD, Ashwell M: A systematic review of waist-toheight ratio as a screening tool for the prediction of cardiovascular disease and diabetes: 0.5 could be a suitable global boundary value. Nutr Res Rev 2010, 23:247-269.

30. O'Brien E, Asmar R, Beilin L, Imai Y, Mancia G, Mengden T, Myers M, Padfield P, Palatini P, Parati G, Pickering T, Redon J, Staessen J, Stergiou G, Verdecchia P: Practice guidelines of the European Society of Hypertension for clinic, ambulatory and self blood pressure measurement. J Hypertens 2005, 23:697-701.

31. Mancia G, De Backer G, Dominiczak A, Cifkova R, Fagard R, Germano G, Grassi G, Heagerty AM, Kjeldsen SE, Laurent S, Narkiewicz K, Ruilope L, Rynkiewicz A, Schmieder RE, Boudier HA, Zanchetti A, Vahanian A, Camm J, De Caterina R, Dean V, Dickstein K, Filippatos G, Funck-Brentano C, Hellemans I, Kristensen SD, McGregor K, Sechtem U, Silber S, Tendera M, Widimsky P, et al: 2007 Guidelines for the Management of Arterial Hypertension: The Task Force for the Management of Arterial Hypertension of the European Society of Hypertension (ESH) and of the European Society of Cardiology (ESC). J Hypertens 2007, 25:1105-1187.

32. Touboul PJ, Hennerici MG, Meairs S, Adams H, Amarenco P, Bornstein N, Csiba L, Desvarieux M, Ebrahim S, Fatar M, Hernandez Hernandez R, Jaff M, Kownator S, Prati P, Rundek T, Sitzer M, Schminke U, Tardif JC, Taylor A, Vicaut E, Woo KS, Zannad F, Zureik M: Mannheim carotid intima-media thickness consensus (2004-2006). An update on behalf of the Advisory Board of the 3rd and 4th Watching the Risk Symposium, 13th and 15th European Stroke Conferences, Mannheim, Germany, 2004, and Brussels, Belgium, 2006. Cerebrovasc Dis 2007, 23:75-80.

33. Hirsch AT, Haskal ZJ, Hertzer NR, Bakal CW, Creager MA, Halperin JL Hiratzka LF, Murphy WR, Olin JW, Puschett JB, Rosenfield KA, Sacks D, Stanley JC, Taylor LM Jr, White CJ, White J, White RA, Antman EM, Smith SC $J$ r, Adams CD, Anderson JL, Faxon DP, Fuster V, Gibbons RJ, Hunt SA, Jacobs AK, Nishimura R, Ornato JP, Page RL, Riegel B: ACC/AHA Guidelines for the Management of Patients with Peripheral Arterial Disease (lower extremity, renal, mesenteric, and abdominal aortic): a collaborative report from the American Associations for Vascular Surgery/Society for Vascular Surgery, Society for Cardiovascular Angiography and Interventions, Society for Vascular Medicine and Biology, Society of Interventional Radiology, and the ACC/AHA Task Force on Practice Guidelines (writing committee to develop guidelines for the management of patients with peripheral arterial disease)-summary of recommendations. J Vasc Interv Radiol 2006, 17:1383-1397, quiz 1398.

34. Montagne $P$, Laroche $P$, Cuilliere ML, Varcin P, Pau B, Duheille J: Microparticle-enhanced nephelometric immunoassay for human Creactive protein. J Clin Lab Anal 1992, 6:24-29.

35. Yan RT, Yan AT, Anderson TJ, Buithieu J, Charbonneau F, Title L, Verma S, Lonn EM: The differential association between various anthropometric indices of obesity and subclinical atherosclerosis. Atherosclerosis 2009, 207:232-238.

36. Maher V, O'Dowd M, Carey M, Markham C, Byrne A, Hand E, Mc Inerney D: Association of central obesity with early Carotid intima-media thickening is independent of that from other risk factors. Int J Obes (Lond) 2009, 33:136-143.

37. De Michele M, Panico S, lannuzzi A, Celentano E, Ciardullo AV, Galasso R, Sacchetti L, Zarrilli F, Bond MG, Rubba P: Association of obesity and central fat distribution with carotid artery wall thickening in middleaged women. Stroke 2002, 33:2923-2928.

38. Kizer JR, Biggs ML, Ix JH, Mukamal KJ, Zieman SJ, de Boer IH, Mozaffarian D, Barzilay Jl, Strotmeyer ES, Luchsinger JA, Elkind MS, Longstreth WT Jr, Kuller LH, Siscovick DS: Measures of adiposity and future risk of ischemic stroke and coronary heart disease in older men and women. Am J Epidemiol 2011, 173:10-25.

39. Tison GH, Ndumele CE, Gerstenblith G, Allison MA, Polak JF, Szklo M: Usefulness of baseline obesity to predict development of a high ankle brachial index (from the Multi-Ethnic Study of Atherosclerosis). Am J Cardiol 2011, 107:1386-1391.

\section{Pre-publication history}

The pre-publication history for this paper can be accessed here: http://www.biomedcentral.com/1471-2261/12/3/prepub

doi:10.1186/1471-2261-12-3

Cite this article as: Recio-Rodriguez et al:: Abdominal obesity vs general obesity for identifying arterial stiffness, subclinical atherosclerosis and wave reflection in healthy, diabetics and hypertensive. BMC Cardiovascular Disorders 2012 12:3.

\section{Submit your next manuscript to BioMed Central and take full advantage of:}

- Convenient online submission

- Thorough peer review

- No space constraints or color figure charges

- Immediate publication on acceptance

- Inclusion in PubMed, CAS, Scopus and Google Scholar

- Research which is freely available for redistribution

Submit your manuscript at www.biomedcentral.com/submit
C Biomed Central 